\title{
The European Research Council @ 10: whither hopes and fears? ${ }^{1}$
}

Approximately as appears in European Political Science 2018

\begin{abstract}
While ten years is too early to draw broad conclusions, the European Research Council does seem to have succeeded in promoting excellent and basic research in Europe, both through its own projects and by affecting standards and aspirations more broadly. It has affected widely shared conceptions of scholarly excellence and introduced new measures of academic esteem with more attention to rigorous peer review - also in the social sciences and the humanities. One concern is that the portability of grants may have fueled the clustering of research talent and reputation toward some institutions and some states, away from others. The benefits of the ERC in promoting research quality across Europe in the longer term may be at risk unless some parties take steps to correct the imbalance.
\end{abstract}

The European Research Council (ERC) was established in 2007 with the objective to encourage high quality research in Europe through competitive funding and to support investigator-driven frontier research across all fields. The criterion for selection was to be scientific excellence alone. Has the ERC lived up to the hopes, fears and aspirations of the research community - scholars, universities, funding bodies, governments and the EU - in social science and the humanities (SSH)? One fruitful starting point may be some hopes and fears stated before the ERC started: "pro and con of an ERC for the social sciences and humanities" (Follesdal 2006).

\section{6 - SOME BACKGROUND}

A wide spread perception had been percolating since the late 1990s that European research was lagging drastically behind the US. Academics, domestic politicians and the EU shared this concern, albeit for different reasons.

\footnotetext{
${ }^{1}$ About the author: Andreas Follesdal. Professor of Political Philosophy, Faculty of Law $\underline{\text { University of }}$ Oslo. Ph.D. 1991 in Philosophy, Harvard University. Co-Director of PluriCourts, a Centre of Excellence for the Study of the Legitimate Roles of the Judiciary in the Global Order. Principal Investigator, European Research Council Advanced Grant MultiRights 2011-16, on the Legitimacy of Multi-Level Human rights Judiciary. Past member of ERC panels SH2 and SH4.
}

The observations and research leading to this article was partially funded by the European Research Council under the European Union's Seventh Framework Programme (FP7/2007-2013) / ERC Advanced Grant agreement $n^{\circ} 269841$ - MultiRights, and partly supported by the Research Council of Norway through its Centres of Excellence Funding Scheme, project number 223274 - PluriCourts The Legitimacy of the International Judiciary. A draft version was presented at a panel on "the ERC @ 10: what has it done to us?" at the ECPR General Conference in Oslo, September 8, 2017. I am grateful for comments received then and afterwards, especially from Thomas König and Geir Ulfstein. 


\section{EU POLICIES PART OF THE PROBLEM}

Seen from the vantage point of SSH, several EU policies were part of the problem facing European research. Many hoped that the ERC become part of the solution (For details of the processes of Gornitzka et al. 2014 and König 2017).

1. The Bologna process for higher education sought to promote European mobility and international competition with the US. Some feared the process would force institutions of higher education onto a non-sustainable strategy of priority to education at the long term expense of research.

2. The Lisbon process focused on economic growth and job creation, often with an overloaded and uncoordinated policy agenda. The objective to "improve the effectiveness of investments in education" was to be measured solely by standards of short term job creation and economic comparative efficiency (Barroso, 2005). Unless supplemented by other perspectives, this narrow policy focus would extinguish other important societal contributions of SSH. In particular, research on topics less directly relevant for the twofold objectives of growth and jobs, such as basic research, would be underfunded.

3. Many scholars thought the EU Framework Programmes had marginalized the $\mathrm{SSH}$, and were likely to continue to do so. Insofar as EU funding also drained domestic resources, this marginalisation hit the SSH hard - challenging popular claims that all competition brings Pareto improvements.

\section{THE COMMISSION LOOKING FOR PROBLEMS TO SOLVE}

In 2006 the European Commission appeared to be looking for problems it could solve, where joint European Union efforts could be justified as part of the solution. Which EU action might identify and tap the alleged value added to national research policies by European research collaboration? Some arguments for the necessity of EU action in particular seemed overdrawn, even then. Certainly, European level action might foster exchange of ideas, data and comparative research. But many such services were already secured by the ECPR, European Political Science and other arenas.

Such ignorance of existing European wide research collaboration notwithstanding, in 2006 an ERC might bring several benefits. The ERC might secure economies of scale, it might help alleviate coordination problems, and might help obtain some public goods or 'club goods' for SSH. An ERC could

- promote data sharing and large comparative projects

- increase public understanding of the value and appreciation of the SSH

- foster basic and critical SSH that is needed for the full set of EU objectives in the long run, not only those that seem to serve job creation in the near future.

Since basic research is often by its very nature a public good, it is likely to be undersupplied by uncoordinated national authorities. And short-sighted domestic authorities with 4 year political accountability cycles might not want to fund sufficiently independent, basic or critical research. Such problems could be avoided if the ERC would be sufficiently immune from pressures toward short term usefulness, 
and independent enough to fund critical research.

\section{TOWARD ASSESSMENT}

\section{PRO 'BASIC RESEARCH' AND MULTIDISCIPLINARY PROJECTS}

The ERC did indeed strive to be independent from its very beginning. When the Secretariat suggested to assess applications for " potential impact" of the research proposal or for their "innovation and social/economic benefits," the Scientific Council members reacted almost allergically.' (König 20177, 107). However, the continued pressures against such objectives within the EU should not be underestimated (König 20177). And the ERC has checked whether the research does have such benefits.

The ERC does appear to enhance the status of basic research in various domestic and European research funding bodies - as a model of high quality 'open skies' research (Nature 2016). Furthermore, the ERC's priority for "ground breaking research" appears to promote multi-disciplinary research. This often occurred by applying research beyond its original field, or by interaction among hitherto unrelated fields (European Research Council 2016b, 6).

Has the ERC promoted high quality research? Again, it may be too early to tell, and the relative attraction of the US and the EU for researchers is due to several further causes. Still, it may be possible to discern some effects regarding innovative research. The ERC has published a report concerning its success in funding groundbreaking research. It is of course very difficult to disentangle the effect of ERC funding for researchers who may have secured other funding than that of the ERC. The report does not distinguish SSH research from other disciplines but it indicates inter alia that ERC projects have led to a very high number of highly cited publications (European Research Council 2016b, 1). Approximately 71\% of the evaluated projects have led to a 'major scientific advance' or a 'scientific breakthrough'. (European Research Council 2016b, 4). Possibly to deflect criticism that the ERC funds useless research, and somewhat more speculative, the report found that just under $80 \%$ of the projects could potentially have some impact on the economy, society and policy making. (European Research Council 2016b, 4).

\section{THE ERC'S LONG TERM SYSTEMIC IMPACTS}

That the ERC would have broader effects was foreseen and partly welcomed. Among concerns mentioned in 2006 were to avoid centralization of research funding to the ERC and to avoid full harmonization of standards and procedures. At a time when competition is supposed to foster excellence in research, research academies and private funding bodies must continue to compete with the ERC, to help foster excellence not only among researchers but also among public research funding bodies. So European level action should not fully harmonize national and European research funding efforts, including the European Science Foundation.

What has happened so far? It is clear that the ERC has aimed to stimulate borrowing of best practices from wherever they are found, and to promote 'positive 
contamination' within the whole European research system (König 2017, 101). What sorts of harmonization and other shifts have occurred? One striking and unexpected range of impacts are due to the 'portability' of the ERC grants, so that the grant holders may (threaten to) take the grant with them and move to better host institutions. Approximately $20 \%$ of starting grant recipients conduct their research abroad (Huber et al. 2015, cf Beerkens 2018).

\section{STRENGTHEN CRITERIA OF RESEARCH EXCELLENCE BY PEER REVIEW}

For the ERC to promote excellent research in Europe it must maximize its credibility as funder of high quality research. It must give priority to academic excellence over EU policy agenda relevance and geographical spread - and target audiences must be convinced of this. The ERC can establish and maintain a reputation for selecting high quality 'investigator driven' project proposals only if its processes are transparent, simple, with low administrative burdens and with measurement standards and peer review processes appropriate for $\mathrm{SSH}$ research.

In 2006, one concern was that in SSH, the quality standards would have to be somewhat different than international journal bibliometrics common in the natural sciences. Natural scientists and quantitatively oriented social scientists had created bibliographic measures that fail to reflect fully the focus on local topics, local languages, and monograph traditions of the SSH. The ERC would have to develop measurement standards and processes that would include appropriate forms of national and international peer review. This would be required to measure and promote excellent research in humanities and law.

How has the ERC pursued this objective, and how can we assess its achievement? The ERC certainly realized that it can ensure 'excellence through competition' only if "the decision-making procedure would be commonly and convincingly perceived as fair, reliable, and funding the proper proposals." (König 2017). The ERC has indeed fine tuned the peer review mechanism, and is open to other than bibliometric indicators of academic excellence where appropriate.

\section{IMPACT ON YOUNG RESEARCHERS - PORTABILITY IS POWER}

Important effects of the ERC concern younger researchers' career plans, with great repercussions to the research landscape as a whole. The ERC grants have taken on symbolic functions that affect the European research landscape. Among the more than 110000 PhDs recipients every year in Europe (Toom 2017, 250), less than 400 will receive an ERC Starting Grant. Still, the ERC has broad ranging effects.

The ERC has changed the standards for who counts as excellent researchers (Edler et al. 2014, Hoenig 2017). The ERC grant holders enjoy a stamp of academic excellence, as do their host institutions. More profoundly, the ERC's understanding of 'scientific excellence' and 'frontier research' affect perceptions of standards of academic quality among universities, funding bodies - and many academics (Edler et al. 2014, Hoenig 2017).

For individual researchers, the ERC shape expectations and strategies. 
Researchers may cluster toward topics that are more interdisciplinary, since the ERC appears to favor those. Researchers may favour CV building measures such as mobility - toward more famous universities - during the PhD studies - to the disadvantage of researchers with obligations of care that hinder such movement. Very many individual researchers decide to allocate time to write ERC applications. The time invested may lead many of them to stick to those research topics even when applying to other funders. Thus very many researchers may end up with projects that are inter-disciplinary, comparative etc.

Will the hope for an ever less likely permanent position increase their motivation to apply for an ERC grant? The prospects of an ERC grant may offer a more predictable career path for the successful applicants. What are the effects on the dozens of thousands of applicants whose proposals were rejected by the ERC: many may understandably be frustrated with their experience with the ERC (Myklebust 2015).

Further important effects stem from the portability of the ERC grants. The researcher can move from one host institution to another in pursuit of better working conditions. The portability of ERC grants seems to boost the existing significant clustering of ECR grants. Several see trends toward an ERC-defined elite segment of scholars, who apply from or migrate toward a segment of elite research institutions, within a segment of (elite) European countries. What are the impacts of this multilevel clustering - on individual researchers, universities, funding bodies, states - and on the EU and on the ERC itself?

The exit option of ERC grantees give them more bargaining power in negotiations with their institution (König 2018). The actual number of ERC grantees who move may be small, for several reasons- among starting grant holders approximately $20 \%$ stayed outside their home country (Huber et al. 2015), others report about $10 \%$ of ERC grantees (Nedeva et al. 2012). The actual mobility trends may be indicative of longer term effects (European Research Council 2016a, Myklebust 2015). Even if the actual number of moves is small, the possibility increases the grantees' relative bargaining power, and may change various policy responses of universities, funding agencies and states. Such pressures may be stronger insofar as some universities are known to poach ERC grantees (Huber et al. 2015, cf Beerkens 2018). These policy shifts may of course benefit researchers generally: The host university might learn to reduce unnecessary bureaucratic hurdles or otherwise facilitate research. All researchers lucky enough to work at such a learning university might enjoy better web pages or simpler time sheets. I myself am not so lucky.

Other benefits may accrue only to the ERC grant holder, such as salary, support staff - and perhaps permanent positions. This meritocracy may well give both new incentives and cause new tensions and resentment. Furthermore, it may expose and enhance universities' different interest in and ability to host ERC scholars (Cruz-Castro et al. 2016). 


\section{IMPACT ON OTHER RESEARCH FUNDING BODIES}

There seems to be broad agreement that the ERC did not become 'an administrative monster' (König 2017, 101) But has the ERC been a role model for other funding agencies? It sometimes listed its comparative advantages as being peer review only, and a less burdensome application - where the obvious but unstated comparison is with other EU funding bodies. (e.g. https://erc.europa.eu/funding/starting-grants; Nature 2011). Again, it is difficult to determine the full extent of the ERC's impact on calls to simplify the Framework programs, but concrete examples include a fixed share of overhead per project, abolishing time sheets for those working $100 \%$ on the project, and electronic reviews rather than paper. The ERC experiences may have shown that simplification need not sacrifice quality when seeking to 'replace Kafka with common sense' (Geoghegan-Quinn 2011).

Several national research funding bodies such as Norway and Austria appear to copy the ERC model of focus on the quality of the individual researcher - the 'Principal Investigator.' (Nedeva et al. 2012, 8, 97-99). This may be because the ERC model itself was borrowed from the life sciences, and/or because this is thought to be a more effective way to distribute funds, and/or because it helps prepare the researchers for later ERC applications.

There does seem to be widespread copying of the ERC's selection processes toward simpler and more transparency concerning the steps, standards and criteria both within Horizon 2020 and within various domestic research funding bodies. Increased attention to the benefits of peer reviewed publications and research stays abroad seem to be positive effects. However, the ERC's focus on peer review mechanisms and outcome specified as publications - even as qualitatively good publications - may have had too much influence - though its impact is difficult to disentangle from other factors. More institutions allocate even more of scare resource funds through competitive bidding - instead of e.g. trusting publishing academics to spend small sums wisely. There is also pressure from several sources, not only from the ERC, to hold researchers to stricter account for funds received. Lists of resultant publications may be among the measures with least harmful perverse incentives.

Has the ERC changed the national research agendas? Such effects may be there, but are difficult to discern: has the ERC's priority for interdisciplinary work (European Research Council 2016b) led to similar priorities domestically? Do domestic research councils provide less funding for topics of solely local or national concern - because the ERC does not fund such projects?

Another area where the ECR might have broader effects concern the transaction costs of application writing. The ERC can ensure 'excellence through competition' only if transaction costs are minimized, both to entice good applicants, recruit good reviewers, and to spend as much as possible of the funds on more projects. A risk for the ERC - as for national funding agencies and universities - is that scholars and research administration staff pour ever more scarce resources into application writing and the peer review assessment thereof. In parts of the SSH the cost-benefit calculation of application writing may be different than in some natural 
sciences, due in part to the possibilities for doing much research at relatively low cost. On the other hand, the ERC model may reduce the resources researchers spend on application writing, - insofar as more application forms are copied from the ERC model.

The ERC may still have promoted excessive transaction costs, by stimulating ever more - costly - applications to the ERC itself. It only funds approximately $9-10 \%$ of the applications (European Research Council 2014, 21). So more than $90 \%$ (close to 8000 applications by 2013) are turned down. How much of the efforts can be reused for other purposes is unclear, but it is clearly a massive cost of resources and lost hopes.

\section{MULTILEVEL CLUSTERS OF EXCELLENCE}

ERC grantees in the SSH are clustered at some universities and research institutes, in the geographical areas of London, Paris, Amsterdam, Oxford, Cambridge (European Research Council 2015, 81). There may be many effects of such meritocratic clusters, giving incentives to young scholars, and to universities and states who seek to attract and keep them, - and possibly on the incentives of states to fund the ERC in the future.

Regarding the impact on universities, some observe a segmentation.

University management must accommodate ERC as a new factor in the global competition for reputation, resources and personnel (Edler et al. 2014). Many universities thus find their strategic opportunity space profoundly affected by the competition for ERC funding. The increased attention and esteem ERC brings to the research tasks of universities may lead some universities to downplay teaching or dissemination. Universities' ability to prioritize some research themes is constrained by the resources committed to ERC applications and projects - unless the ERC grants also bring in more resources not tied directly to implementation of ERC grants. Such is the case in Norway, where the Ministry of Research matches ERC grants with nonearmarked funding to the host institution.

Do universities find themselves forced by the competition to offer tenure to ERC grantees - even as the number of tenured positions diminish? (Cruz-Castro et al. 2016, 368). This may constitute an improvement for some institutions, toward a more objective, less nepotistic process. But it may also skew the hiring processes and research agenda of the university unduly and in unpredictable ways - unless the institution vets applications it will host. Some universities appear to offer to host ERC applications, and grant successful scholars tenure - in effect delegating to the ERC these important strategies concerning the institution's research profile.

A range of universities can adapt more research-conducive routines to facilitate ERC applications, to attract ERC grantees, and to induce them to stay. Other universities don't need to change, and yet others are not willing to or able to reorganize as required. Research on a sample of Spanish universities indicates that the ERC may exacerbate such clustering (Cruz-Castro et al. 2016).

Does the ERC have repercussions for how universities and states address 
some of the severe challenges to recruiting young researchers? It is not obvious that the ERC affects the number of tenured positions - though without the ERC, universities might have hired more academics in permanent positions instead of hiring more administrative staff to assist in application management. Nor does the gender disparity in the academy seem much affected by the ERC. In fact, even when it comes to the measure of success rate of women in social sciences and humanities this is slightly less than that of men (European Research Council 2015, 45-46).

\section{IMPACT ON GOVERNMENTS}

Regarding the impact of the ERC on European states, the benefits of grants are clearly skewed. Six countries hosted about two-thirds of all ERC funded projects (European Research Council 2015, 63). It is not obvious that the ERC can maintain support across enough EU member states if this sort of excellence continues to cluster. We cannot expect all other EU states to continue subsidizing research clusters in some states, - clusters that sometimes seem to poach bright minds before they apply for ERC grants, and sometimes lure recipients to join them.

So the commitment to meritocracy does not lend itself to geographical balancing, and does not necessarily increase the quality of research across Europe. One response among the friends of the ERC may be more concerted efforts to bolster the competence of researchers in 'less successful states' to write successful applications, and to help willing universities understand how they may retain those successes.

Such efforts may be helped or at least profoundly affected by another important change to the European research landscape. So far, $22 \%$ of all ERC grants went to projects at UK institutions (European Research Council 2015, 63). How will Brexit shift the dynamics and centres of gravity?

HAS THE ERC IMPROVED EUROPEAN RESEARCH - COMPARED TO THE US? When our brightest students ask our advice on how and where to pursue a future academic career, where do we point? The Commission correctly identified this as a crucial challenge:

individuals should be stimulated to enter into the researcher's profession, European researchers should be encouraged to stay in Europe, researchers from the entire world should be attracted to Europe and Europe should be made more attractive to the best researchers. (Commission 2005, 6)

Regarding the competition between the EU and the US for researchers, an updated study on the factors affecting the mobility of EU researchers also toward the US is expected in 2018 (www.more3.eu). Still, a study from 2012 indicates some areas where the ERC may affect researchers' motivations (IDEA Consult 2013). In particular, the US remained the most popular destination for EU researchers living outside the EU. Their main motivations appear to include career progression, 
research funding, facilities and equipment, and remuneration (IDEA Consult 2013, 89).

The ERC may possibly affect several of these considerations, insofar as European universities and national funding bodies may create more attractive research career paths to attract and retain ERC scholars - and other strong researchers. Such changes may lead those scholars to stay in Europe.

However, unless enough universities are able and willing to offer competitive conditions, the ERC may also create new risks. Insofar as the ERC label signals academic strength and provides more international visibility to the grantees, the ERC may in fact facilitate US institutions' search for excellence and foster more exit to the US for some of the grantees.

\section{CONCLUSION}

While ten years is too early to draw broad conclusions, the ERC does seem to have succeeded in promoting excellent and basic research in Europe, both through its own projects and by affecting standards and aspirations more broadly. It has affected widely shared conceptions of scholarly excellence and introduced new measures of academic esteem with more attention to rigorous peer review - also in SSH. The portability of grants seems to have further fueled a clustering of research talent and reputation toward some institutions and some states, to the detriment of others. It is not obvious that the benefits of the ERC will help promote research quality across Europe in the longer term - unless some parties take steps to correct the imbalance without risking the reputation for quality.

These first findings and conjectures about trends may be tested more rigorously in the years to come. The ERC is still young, and many of us hope that it will continue - and continue to adjust in light of evidence-based recommendations.

ABOUT THE AUTHOR

Andreas Follesdal Ph.D., Professor of Political Philosophy, Faculty of Law, University of Oslo. Co-Director of PluriCourts, a Centre of Excellence for the Study of the Legitimate Roles of the Judiciary in the Global Order. Principal Investigator, European Research Council Advanced Grant MultiRights 2011-16, on the Legitimacy of Multi-Level Human rights Judiciary. Ph.D. 1991 in Philosophy, Harvard University.

\section{REFERENCES}

Beerkens, M. (2018). 'The European Research Council and the academic profession: Insights from studying starting grant holders'. European Political Science xx

Cruz-Castro, L., Benitez-Amado, A. \& Sanz-Menendez, L. (2016). 'The proof of the pudding: University responses to the European Research Council'. Research evaluation, 2510.1093/reseval/rvw015

Edler, J., Frischer, D. \& Glanz, M. (2014). Funding individuals - changing organisations: The impact of the ERC on universities. In: Whitley, R. \& Glaeser 
J. (eds.) Organizational transformation and scientific change: the impact of institutional restructuring of universities and intellectual innovation. Bingley: Emerald pp. 77-110.

European Research Council, E. (2015). ERC funding activities 2007-2013: Key facts, patterns and trends

European Research Council, E. (2016a). Basic statistics for ERC funding activities [Online]. Available: https://erc.europa.eu/projects-and-results/statistics [Accessed 26. desember 2016

European Research Council, E. (2016b). 'Qualitative Evaluation of completed projects funded by the European Research Council'. European Commission,

European Research Council, E., Executive Agency (2014). 'Science behind the projects: Research funded by the European Research Council in FP7 (20072013)'.

Follesdal, A. (2006). 'A European Research Council for the social sciences and humanities, Pro and Con'. European Political Science, 5: 21-32. DOI: 10.1057/palgrave.eps.2210068

Geoghegan-Quinn, M. (2011). Research and innovation - simpler funding and roadmap towards the new programme [Online]. Available: europa.eu/rapid/pressrelease_SPEECH-11-41_en.doc [Accessed Dec 10 2017].

Gornitzka, Å. \& Metz, J. (2014). Dynamics of Institution Building in the Europe of Knowledge: The Birth of the European Research Council. In: Chou, M.-H. \& Gornitzka, Å. (eds.) Building the Knowledge Economy in Europe: New Constellations in European Research and Higher Education Governance. Elgar pp.

Hoenig, B. (2017). Europe's New Scientific Elite: Social Mechanisms of Science in the European Research Area,

Huber, N., Wegner, A. \& Neufeld, J. (2015). 'Evaluation report on the impact of the ERC starting grant programme'. MERCI (Monitoring European Research Council's Implementation of Excellence). iFQ-Working Paper No. 16. ,

Idea Consult (2013). 'Support for continued data collection and analysis concerning mobility patterns and career paths of researchers'.

König, T. (2017). The European Research Council, Polity.

König, T. (2018). 'Political Science and the European Research Council'. European Political Science, xxx

Myklebust, J. P. (2015). 'Top institutions dominate in fierce ERC grant battle'. University World News,

Nature, E. (2011). Europe cuts funding red tape [Online]. Available: http://www.nature.com/news/2011/111005/full/478016a.html [Accessed Dec 10 2017].

Nature, E. (2016). 'Agencies must show that basic research is worth the investment'. Nature 535

Nedeva, M., Braun, D., Edler, J., Glaser, J., Laredo, P., Laudel, G. \& Whitley, R. (2012). Understanding and Assessing the Impact and Outcomes of the ERC and its Funding Schemes: (EURECIA) Final Synthesis Report., Brussels, European Research 
Council.

Toom, K. (2017). Shaping next generation researchers. In: Andersen, J., Toom, K., Poli, S. \& Miller, P. F. (eds.) Research management: Europe and beyond. Elsevier pp. 249-262. 